\title{
Beyond Bagels and Yoga: Early Detection and Containment in the Burnout Epidemic
}

\author{
Donna M. Windish, MD, MPH ${ }^{1,2}$ and Shalini Reddy, MD, MHPE ${ }^{3}$
}

'Department of Internal Medicine, Yale University School of Medicine, New Haven, USA; ${ }^{2}$ Yale Primary Care Residency Program, New Haven, CT, USA; ${ }^{3}$ Internal Medicine Residency Program, John H. Stroger Hospital of Cook County Health, Chicago, IL, USA.

J Gen Intern Med 34(5):657-8

DOI: $10.1007 / \mathrm{s} 11606-019-04924-9$

(c) Society of General Internal Medicine 2019

I t was the fall of 1998 on a clear beautiful afternoon in New England. The car veered quickly to the left narrowly missing the guardrail on the highway. Although it was daylight, the resident could hardly keep her eyes open as she drove home following a $30+$ hour shift in the MICU. She only had 3 hours of sleep the night before, had not had a day off in over a week, and was physically and mentally exhausted. She felt depressed and wondered if she would be able to exercise later that day or see her friends. Instead, she made it safely home, collapsed on the couch, and woke up the next day just in time to go back to work to care for the sickest patients in the hospital.

Resident well-being and patient safety started to take center stage in 1987 with the New York Bell Commission report. The 2003 and 2011 Accreditation Council on Graduate Medical Education (ACGME) mandates for duty hour reforms limited work hours with the hope that these limitations would improve wellness. Despite these changes, burnout remains prevalent in trainees and can lead to depression, substance use, decreased clinical productivity, patient errors, and suicide. Many residency training programs have implemented local strategies in an attempt to alleviate burnout and improve wellness, with varying degrees of success. This special medical education issue of JGIM features two articles that describe new strategies for improving resident well-being. ${ }^{1,2}$

Residency training has been compared to military boot camp where a group of unrelated individuals are thrown together in a high stress environment for a wellcircumscribed period of time. ${ }^{3}$ Within this crucible, strong bonds are often forged; frequently residents spend more time with each other than with friends or family. Residents may thus be best positioned to recognize colleagues in emotional distress. Zabar and colleagues ${ }^{1}$ sought to train interns in Internal Medicine, General Surgery, and Orthopedic Surgery to identify struggling colleagues. Over the course of 4 years, the investigators assessed 145 residents using a standardized health professional (SHP) Objective Structured Clinical

Published online April 16, 2019
Experience (OSCE). Although the exercise was purportedly to receive sign-out from a SHP, interns were assessed on whether they detected, recognized, and managed problem behaviors concerning for a colleague in distress. The exercise was followed by a short debriefing and teaching session. The majority of participants (60\%) checked on the SHP's emotional state but only a third directed the colleague to seek help. If a participant screened the SHP for depression, they were three times more likely to refer the SHP to seek help. There were no significant differences in identification or referral by type of training program. Barriers to digging deeper are familiar to anyone accustomed to giving feedback: time and discomfort. Participants felt pressured to complete their assigned task of sign-out and were concerned about overstepping professional boundaries. The use of the OSCE format contributes to both the strengths and limitations of this study and while it provides hands-on experiences, it is a resource intensive intervention that is not readily accessible to all programs.

In the second article, Broxterman and colleagues ${ }^{2}$ assessed a voluntary intervention to introduce residents to freely available, confidential, counseling services from their employee assistant program (EAP). Interested residents were scheduled for a 1-hour-long appointment by their program coordinator during the work day in lieu of ambulatory time. Most residents $(79 \%, 41 / 52)$ agreed to participate. A pre-intervention survey found that many residents $(73 \%)$ had not used counseling or support services prior to their EAP visit and almost half (46\%) were not aware of how to schedule an EAP consultation on their own. All aspects of the scheduled visit were viewed as favorable by the residents including (1) appreciating not having to schedule the appointment themselves (96\%), (2) feeling the intervention was valuable $(82 \%)$, and (3) being likely to seek future counseling if needed $(79 \%)$. This brief intervention has the potential to provide many benefits that may positively influence resident well-being. First, the burden, and potential barrier, of scheduling the appointment was taken out of the trainee's hands and placed on the program. Second, sessions occurred during work hours which may have increased the likelihood of attendance. Finally, and most importantly, residents became aware of free confidential mental health services through an active learning process. While the intervention was mainly positive, it was done at a single training program with a small number of residents and their survey response rates after the intervention were low $(68 \%)$. In addition, no long-term 
outcomes were presented. Applying this intervention may be difficult for other residency programs, as it might place an undue burden on program support staff and/or their employer's EAP.

In July 2017, the ACGME mandated that all training programs offer "policies and programs that encourage optimal resident and faculty member well-being." ${ }^{4}$ Before this directive, residency training programs had self-initiated strategies in attempts to alleviate stress, decrease burnout, and improve resident well-being. Interventions have included stress management and reduction training, ${ }^{5}$ Balint training, ${ }^{6}$ protected time to sleep, ${ }^{7}$ self-care workshops,${ }^{8}$ resident support groups, ${ }^{9}$ and incentivized exercise programs, ${ }^{10}$ to name a few. Informal coffee and bagels and ice cream socials have also been employed. But can bagels and yoga alone really improve well-being? Eckelberry-Hunt and colleagues explored factors that could increase resident wellness and decrease burnout. ${ }^{11}$ They found two prominent areas detrimental to wellness: a lack of a supportive environment and not enough time to take care of oneself. They also discovered two factors that might mitigate burnout and improve resident well-being: talking about one's feelings and participating in professional counseling. Broxterman and colleagues addressed all of these wellbeing factors in their EAP counseling intervention. ${ }^{2}$ The OSCE by Zabar and colleagues ${ }^{1}$ addressed some of these factors by empowering trainees to recognize and address a struggling colleague through a peer-to-peer interaction.

These two articles are reminders that, in addition to preventing burnout, we must also recognize that there are sizeable numbers of residents who are already burned out. While we work to improve the clinical learning environment to prevent burnout, we must also manage the epidemic of burnout in which we find ourselves. The World Health Organization model for responding to epidemics can help us frame our interventions more effectively: managing an epidemic requires (1) anticipation and early detection, (2) containment, (3) control and mitigation, and (4) elimination and eradication. ${ }^{12}$

We have spent much time so far in this epidemic of physician burnout on steps 3 and 4 . While we must continue our efforts to eliminate burnout, we must devote equal amounts of time to steps 1 and 2. In addition to improving the clinical learning environment and teaching residents how to manage stress, we must also teach them how to recognize and respond to a colleague who is suffering. During their careers, each of our trainees will undoubtedly encounter a colleague like the standardized health professional in Zabar's study. We must equip residents with words and phrases they can use to help their colleagues. While we have robust and often onerous requirements to preempt serious problems such as breaches to patient privacy, we have little to preempt breaches to physician wellbeing. Perhaps, as Broxterman's study suggests, it is time for program directors to mandate self-care in the same way that we mandate training for corporate compliance, infection control, and duty hour logs.

Corresponding Author: Donna M. Windish, MD, MPH; Yale Primary Care Residency Program, 1450 Chapel Street, Private 304, New Haven, CT 06511, USA (e-mail: donna.windish@yale.edu).

\section{Compliance with Ethical Standards:}

Conflict of Interest: The authors declare no conflict of interest.

Publisher's Note: Springer Nature remains neutral with regard to jurisdictional claims in published maps and institutional affiliations.

\section{REFERENCES}

1. Zabar S, Hanley K, Horlick M, Cocks P, Altshuler L, Watsula-Morley A, Berman R, Hochberg M, Phillips D, Kalet A, Gillespie C. "I cannot take this anymore!": Preparing interns to identify and help a struggling colleague. J Gen Intern Med (SPI 4886). https://doi.org/10.1007/ s11606-019-04886-y

2. Broxterman J, Jobe A, Altenhofen D, Eck L. Promoting resident wellbeing through programmatic scheduled wellness consultation. J Gen Intern Med (SPI 4877). https://doi.org/10.1007/s11606-019-04887-x

3. Ziegler JL, Strull WM, Larsen RC, Martin AR, Coates TJ. Stress and medical training. West J Med. 1985 Jun;142(6):814-9.

4. ACGME Common Program Requirements. https://www.acgme.org/Portals/0/PFAssets/ProgramRequirements /CPRs_2017-07-01.pdf. Accessed online January 29, 2019.

5. Bragard I, Etienne AM, Merckaert I, Libert Y, Razavi D. Efficacy of a comminication and stress management training on medical residents' self-efficacy, stress to communicate, and burnout: a randomized controlled study. J Health Psychol. 2010;15(7):1075-81.

6. Ghetti C, Chang J, Gosman G. Burnout, psychological skills, and empathy: balint training in obstetrics and gynecology residents. J Grad Med Educ. 2009;1(2):231-5.

7. Shea JA, Bellini LM, Dinges DF, et al. Impact of protected sleep period for internal medicine interns on overnight call on depression, burnout, and empathy. J Grad Med Educ. 2014;6(2):256-63.

8. Martins AE, Davenport MC, Del Valle MP, Di Lalla S, Dominguez $\mathbf{P}$, Ormando L, Ingratta A, Gambarini H, Ferrero F. Impact of a brief intervention on the burnout levels of pediatric residents. J Pediatr (Rio J). 2011;87(6):493-8.

9. Satterfield JM, Becerra C. Development challenges, stressor, and coping strategies in medical residents: a qualitative analysis of support groups. Med Educ. 2010;44(9):908-916.

10. Weight CJ, Sellon JL, Lessard-Anderson CR, Shanafelt TD, Olsen KD, Laskowski ER. Physical activity, qulaity of life, and burnout among physician trainees: the effect of a team-based, incentivized exercise program. May Clin Proc. 2013;88(12):1435-42.

11. Eckleberry-Hunt J, Lick D, Boura J, Hunt R, Balasubramaniam M, Mulhem E, Fisher C. An exploratory study of resident burnout and wellness. Acad Med. 2009;84(2):269-77.

12. Managing epidemics: key facts about major deadly diseases. Geneva: World Health Organization; 2018. License: CC BY-NC-SA 3.0 IGO. 